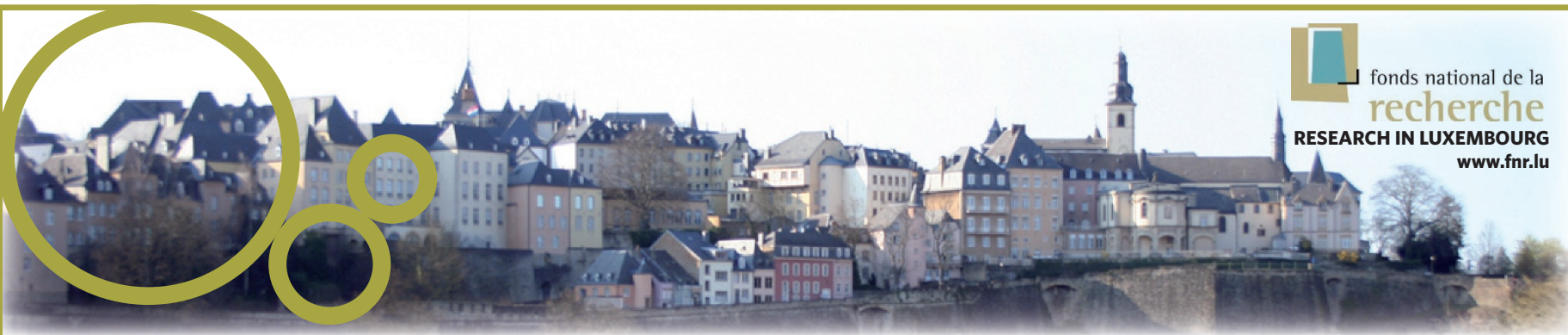

Luxembourg's National Research Fund (FNR) was set up in 1999 to stimulate public research activities in Luxembourg with the aim to strengthen existing and create new competence and knowledge, as well as to increase Luxembourg's attractiveness as a scientific and economic site of excellence through the development of national and international synergies. Currently, the FNR is carrying out a national Foresight exercise, together with the Luxembourg Ministry of Research and the actors involved in Luxembourg research, in order to identify future research domains and priority axes for Luxembourg. In the light of the growing budget and to further increase Luxembourg's attractiveness, the FNR attaches great importance to international cooperation and mobility.

\title{
INTERNATIONAL COOPERATION
}

The FNR has joined several international organisations and networks and is very active on the international level through its multi-annual programme INTER: Promotion of International Cooperation. INTER helps Luxembourg researchers to participate in already existing international programmes or in programmes that are developed jointly with other research funds or councils outside Luxembourg. So far, INTER has facilitated cooperation between Luxembourg researchers and institutions or organisations such as the National Science Foundation (USA), the Service fédéral public de programmation scientifique (Belgium), the European Networks ERA-Net MATERA and ERA-AGE or the European Science Foundation.

\section{MOBILITY}

\section{The FNR has developed two main tools to encourage mobility of researchers and students:}

- the ATTRACT programme offers outstanding international researchers the opportunity to set up a research team within a public-sector research institution in Luxembourg;

- the Mobility Fellowship helps foreign researchers to do research in a Luxembourg institution and Luxembourg researchers to spend time in an institution abroad. Additionally, the Research Ministry's fellowship Bourses de Formation-Recherche enables foreign and Luxembourg PhD students or post-docs to participate in an R\&D project that is of interest to Luxembourg.

\section{Useful links in Luxembourg:}

- Ministry of Research

- University of Luxembourg

- Luxinnovation

- Public Research Centre Gabriel Lippmann

- Public Research Centre Henri Tudor

\section{www.recherche.lu \\ www.uni.lu \\ www.luxinnovation.lu \\ www.lippmann.lu}

www.tudor.lu
- Public Research Centre Santé

- CEPS/Instead

- National Health Laboratory

- National Museum of Natural History www.crp-sante.lu

www.ceps.lu

www.Ins.lu

www.mnhn.lu

For further information on research activities in Luxembourg visit the National Research Fund's website www.fnr.lu as well as the Luxembourg Portal for Innovation

and Research www.innovation.public.lu.

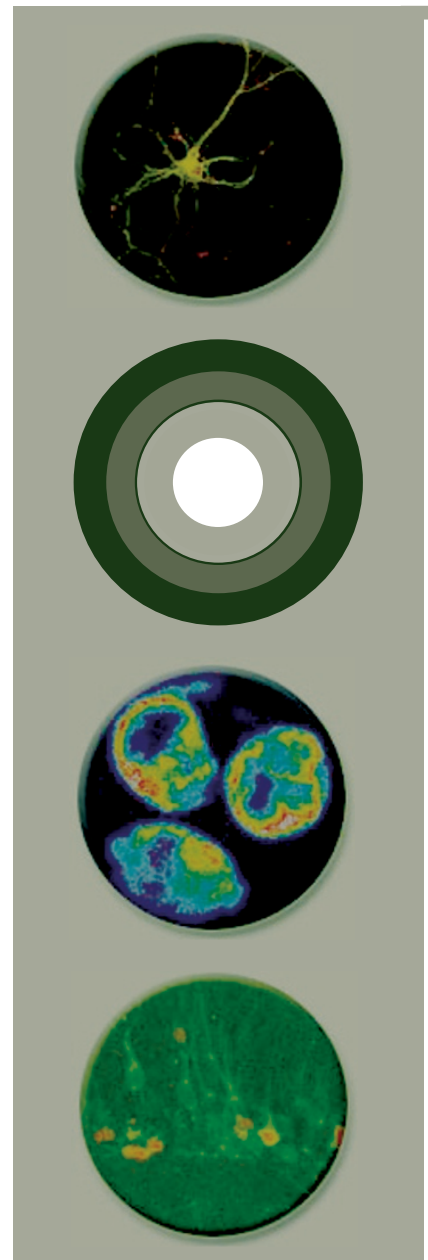

\section{GROUP LEADER IN NEUROSCIENCE}

The Bordeaux INSERM Research Center in Neurosciences together with the Center for Functional Genomics are seeking highly motivated candidate group leaders to create their independent group.

The INSERM Institute for Neuroscience is part of a federation of five Neuroscience Departments (www.inb.u-bordeaux2.fr) at the Bordeaux University that totalise over 40 research groups in all fields from Nano-Imaging of receptor trafficking to cognition. The Center for Functional Genomics (www.pgfb.u-bordeaux2.fr) has a core facility in optical imaging equipped with leading edge technologies (www.picin.u-bordeaux2.fr).

Successful candidates are expected to develop research in the field of Optical Imaging for Neuroscience, from cellular/molecular to in vivo imaging to investigate basic properties of the brain. The candidates should possess strong background in optical imaging and an excellent publication record. Previous experience in the field of Neuroscience is an advantage but not required. We also encourage outstanding candidates from other fields of Neuroscience to apply.

$\mathrm{CVs}$, statement of research interests (3 pages max) and 3 letters of recommendation should be sent to U862@bordeaux.inserm.fr. Deadline for applications, August 31, 2007.

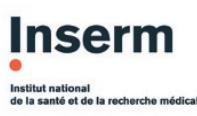

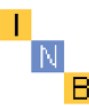




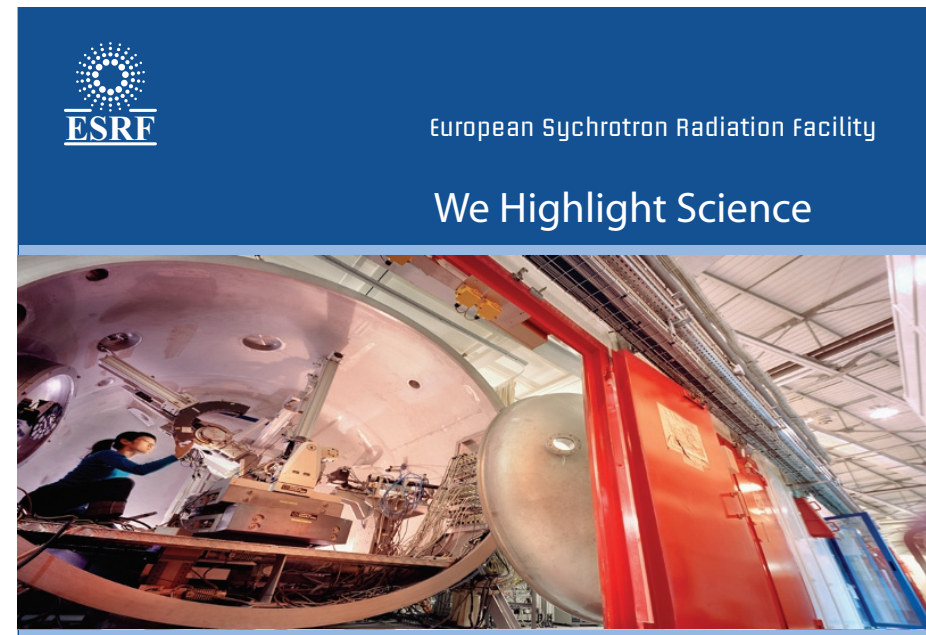

Physics and Chemistry, Life Sciences and Medicine, Earth and Environmental Sciences, Surface and Materials Sciences. The European Synchrotron Radiation Facility (ESRF) is Europe's most powerful light source. The ESRF offers you an exciting opportunity to work with international teams uing synchrotron light in Grenoble, in the heart of the French Alps.

Have a look af our vacancies at www.esrf.eu/jobs

Contact us at recruitment@esrf.eu

Scientists - Post doctoral fellows - PhDstudents - Engineers - Technicians - Administrative stoff

European Synchrotron Radiation facilit!

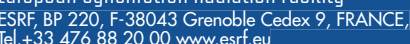
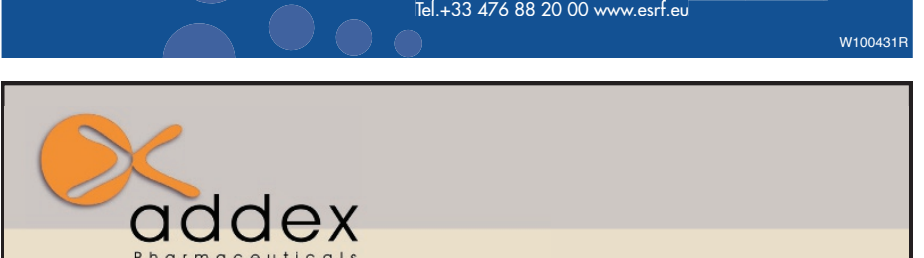

Addex Pharma is an innovative pharmaceutical company that discovers and develops novel therapeutics that modulate the effect of natural activators on their specific targets in a noncompetitive manner, concentrating in particular on GPCRs. These compounds are referred to as allosteric modulators and potentially offer advantages over conventional agonist and antagonist compounds. The company has a portfolio of proprietary compounds in discovery and development for GERD, migraine, anxiety, smoking cessation, depression, pain, cognitive impairment, schizophrenia and Parkinson's disease.

Based in Geneva, Addex is actively recruiting candidates interested in a unique opportunity for long-term professional and personal development. Addex provides an exciting environment and a challenging place to work, where you can see your contributions make a difference.

Current jobs opening at Addex for Biochemists/in vitro Pharmacologists are:

o Allosteric Modulation Platform Group: Research Scientist, Technician

o High-Throughput Screening Group: Laboratory Head, Research Scientist, Technician

Current jobs opening at Addex for Biochemists and Chemists are:

o CNS Therapeutic Disease Area: Group Leader, Laboratory Head, Technician

- Metabolic Disease Therapeutic Area: Group Leader, Laboratory Head, Technician

For more details, check our website: http://www.addexpharma.com

12 Chemin des Aulx, CH-1228, Plan-les-Ouates, Geneva

\section{HHMI}

HOWARD HUGHES MEDICAL INSTITUTE

\section{Laboratory of Human Genetics of Infectious Diseases, Paris, France}

Three post-doctoral research positions in Human Genetics of Infectious Diseases

Applications are invited for three Postdoctoral Research Fellows to join the Laboratory of Human Genetics of Infectious Diseases at Necker Hospita and Research Centre. This laboratory is a world leader in the field of Human Genetics of Infectious Diseases as demonstrated by its main recen publications (Alcais et al. Nature Genetics 2007; Casrouge et al. Science. 2006. Vogt et al. Nature Genetics 2005 ; Mira et al, Nature 2004; Picard et al, Science 2003; Dupuis et al, Science 2001).

The fellows would explore the molecular genetic basis of human infectious diseases, following candidate-gene and/or genome-wide approaches. Depending on the applicant's scientific interest, her/his project may aim to decipher a novel primary immunodeficiency or to exploit known genetic defects for immunological purposes. Monogenic and/or complex traits may be studied. Infectious diseases investigated in the laboratory include mycobacterial, pneumococcal, and herpetic diseases.

The Laboratory of Human Genetics of Infectious Diseases is international. The two languages of communication in the laboratory are French and English. About one third of the 24 laboratory's members are French. The others originate from 10 countries from Europe, the Americas, Africa, and Asia.

No specific medical and/or scientific qualification is requested, besides either doctoral degree. A strong motivation is an absolute must. Independent and interactive candidates are preferred.

A post-doctoral salary will be guaranteed for at least three years. Candidates should send their CV, cover letter, statements of current and future research interests (1 page), publication track record and the names and addresses/e-mails contacts of at least two academic referees.

For informal inquiries please contact casanova@necker.fr or abel@necker.fr

Please send full application to:

Pr. Jean-Laurent Casanova

Director, Laboratory of Human Genetics of Infectious Diseases

University of Paris René Descartes-INSERM U550

Necker-Enfants Malades Medical School, 156 rue de Vaugirard

75015 Paris, France, EU

Voice 33140615687 (office) or

5381 (secretary)

Fax 33140615688

E-mail casanova@necker.fr

web site : http://www.hgid.net

\section{Inserm} W100001RM

\section{UNIVERSITÉ DE GENĖVE}

The Faculty of Sciences invites applications for a position as

\section{ASSOCIATE PROFESSOR} (PROFESSEUR-E ADJOINT-E)

at the Department of Astronomy

in search of extra-solar planets by spectroscopic, astrometric and photometric methods.

ASSIGNMENT : Full-time appointments comprising six hours of lectures per week. The successful candidate is expected to conduct a research group.

ACADEMIC TITLE REQUESTED : PhD or equivalent. Teaching experience would be appreciated.

STARTING DATE : January 1, 2008 or upon mutual agreement.

Applications should be submitted in written form and sent before June 8, 2007 to the following address :

Administrateur, Faculté des Sciences

Quai Ernest-Ansermet 30, 1211 Genève 4, SWITZERLAND

From whom further information concerning the job description and working conditions may be obtained.

Applications from women are particularly welcome. 


\section{Call for EUROCORES themes}

ESF is looking for new ideas for collaborative research at the European level. We invite well developed proposals for new EUROCORES Programmes (EUROCORES themes).

The European Science Foundation (ESF) provides a platform for its Member Organisations to advance European research and explore new directions for research at the European level. Established in 1974 as an independent non-governmental organisation, the ESF currently serves $\mathbf{7 5}$ member organisations in 30 European countries. The ESF is devoted to the coordination, implementation, networking and science policy development in the basic sciences. The ESF wishes to contribute to the European Research Area with the EUROCORES Scheme.

\section{The EUROCORES Scheme}

The ESF European Collaborative Research (EUROCORES) Programmes offer a flexible framework for researchers from Europe to work on questions which are best addressed in larger scale collaborative research programmes. EUROCORES Programmes allow national research funding organisations in Europe and beyond to support top class research in and across all scientific areas, by matching the needs articulated by the scientific community with their strategic priorities.

\section{Eligibility criteria}

Proposing groups must include scientists and/or representatives from national funding organisations from at least four different countries with ESF membership.
Criteria for the selection of EUROCORES themes

- Scientific quality, novelty and feasibility of the EUROCORES theme proposal

- Requirement for European collaboration

- Relationship to other ongoing/planned research initiatives

in the field (national, European, international)

- Qualifications of the proposers

- Appropriateness of funding requested

How to submit a EUROCORES theme proposal

EUROCORES theme proposals must be submitted online

by 1st June 2007 midday (CET). Proposals are submitted at

www.esf.org/eurocores. The full Call with detailed information and proposal guidelines can also be found at this web address or contact the EUROCORES Scheme at eurocores@esf.org.

The EUROCORES Scheme is currently supported by the EC Sixth Framework Programme under Contract no. ERAS-CT-2003-980409.

For further information on the calls and all ESF activities,

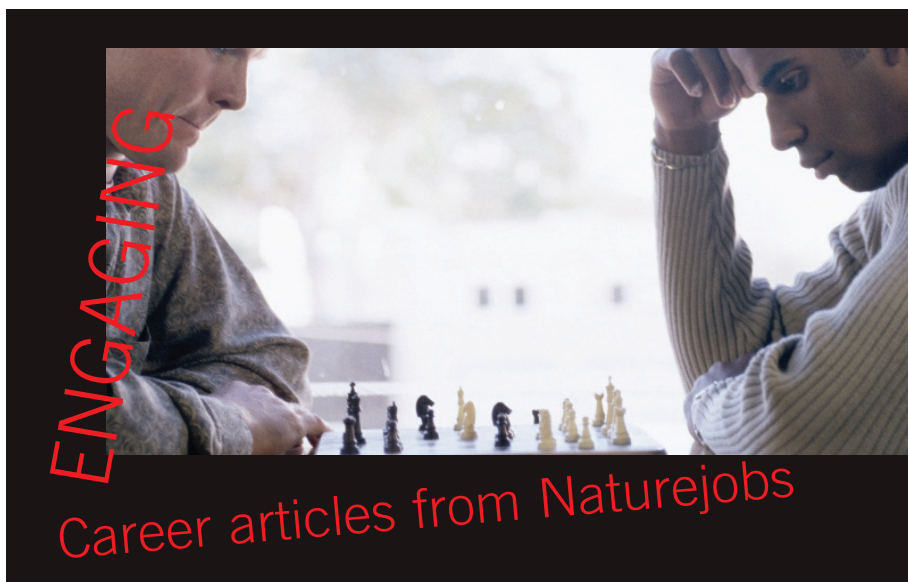

Ateliers de formation Inserm

101 rue de Tolbiac

75654 Paris Cedex 13 France

Tel: 33 (0) 144.23.62.03

Fax: 33 (0) 144.23.62.93

ateliers@tolbiac.inserm.fr

\section{Atelier de formation 180 :}

Protein Interaction Networks: from bioinformatics to cellular dynamics

PHASE

Critical assessment October 4-5, 2007 La-Londe-Les-Maures (Toulon)

The organisation of proteins into macromolecular complexes is an essential element of all cellular functions. Large-scale protein-protein interaction screens revealed that proteins often oligomerize and are part of multiprotein complexes that are embedded into large interaction networks. Today, the scientific community has gathered information on hundreds of protein interactions and bioinformatics will play an increasingly important role to edit these data. The challenge now will be to understand the dynamics (assembly, disassembly, relocalisation) of these complexes. Most recent technological advances

The study of the localisation and the dynamics of compliving cell. The study of the localisation and the dynamics of complexes is not only important for a better knowledge of establishment of new therapeutic strategies.

Audience

- Naturejobs Prospect: quick takes on career implications of

current events

- Naturejobs Special Report: examinations of jobs issues on both sides of the bench

- Naturejobs Careers \& Recruitment: discipline-by-discipline exploration of opportunities

- Naturejobs Regions: tours of scientific hubs

- Naturejobs Movers: traffic reports that follow high-profile scientific globe-trotters and sector-hoppers

- Naturejobs Postdocs \& Students: guides to taking a step toward a permanent position

www.naturejobs.com

\section{$\underset{\text { makng soconoco worke }}{\text { natos }}$} nature publishing group npg

PhD students, post-docs, researchers and research engineers working at research facilities or in research group with interest in cell biology, molecular signaling, monitoring of the dynamics of protein complexes in intact cells, the development of inhibitors of protein-protein interaction.

Conferences will be given in English.

Maximum number of participants : 80

Programme

The conferences will focus on the most powerful techniques for the analysis of macromolecular complexes by 1. presenting the principle of each technique (BRET, FRET, HTRF, FCS, real-time fluorescence microscopy with quantum dots, cryo-electron tomography, reverse mammalian protein-protein interaction trap, MAPPIT), 2. presenting specific examples for each technique,

3. discussing the impact of bioinformatics on analyse and management of interaction networks,

4. helping to make the right choice for the right techniques and bioinformatics tools ( 2 round tables),

5. applying these techniques to the screening of inhibitors of protein-protein interactions in living cells.

Phase II

Practical course November, 2007 Paris

Programme

Practical introduction to microscope-based (FRET, ICS) or microtiter plate-based (BRET, HTRF) techniques to monitor protein interaction

Selection

15 participants will be selected among the participants in phase

Avec la participation de • Hervé Ansanay (Bagnols-sur-Cèze, France), Wolfgang Baumeister (München, Germany), Michel Bouvier (Montréal, Canada), Christine Brun (Marseille, France), Michele Digman (Irvine, USA), Benoît Dubertret (Paris, France), Enrico Gratton (Irvine, USA), Tarik Issad (Paris, France), Stefano Marullo (Paris, France), Atsushi Miyawaki (Hirosawa, Japan), Jan Tavernier (Ghent, Belgium), Marc Tramier 
Since the creation of IRIC in 2003, we have been recruiting the best scientists world-wide, with a view to achieving full capacity with some 500 graduate students, postdoctoral trainees, principal investigators and professionals by 2010 .

With currently 22 highly performing research teams and more than 250 students and researchers from 25 countries, we represent the first high profile institute in Canada dedicated to addressing cancer and immunology using an integrative, multidisciplinary approach. State-of-the-art core facilities including High Throughput Screening, Bio-Imagery, Flow Cytometry, Bioinformatics, Histology, Proteomics, Genomics, Animal Facility and Transgenesis, NMR and biophysics, provide an outstanding resource for both research and training. Our unique teaching program is tailored to training tomorrow's researchers in cancer and immunology with a systems biology perspective.

We are located in the heart of the Universite de Montréal campus, along with a major life sciences cluster, in a city offering an exceptional quality of life with convenient connections with any destination in North America.
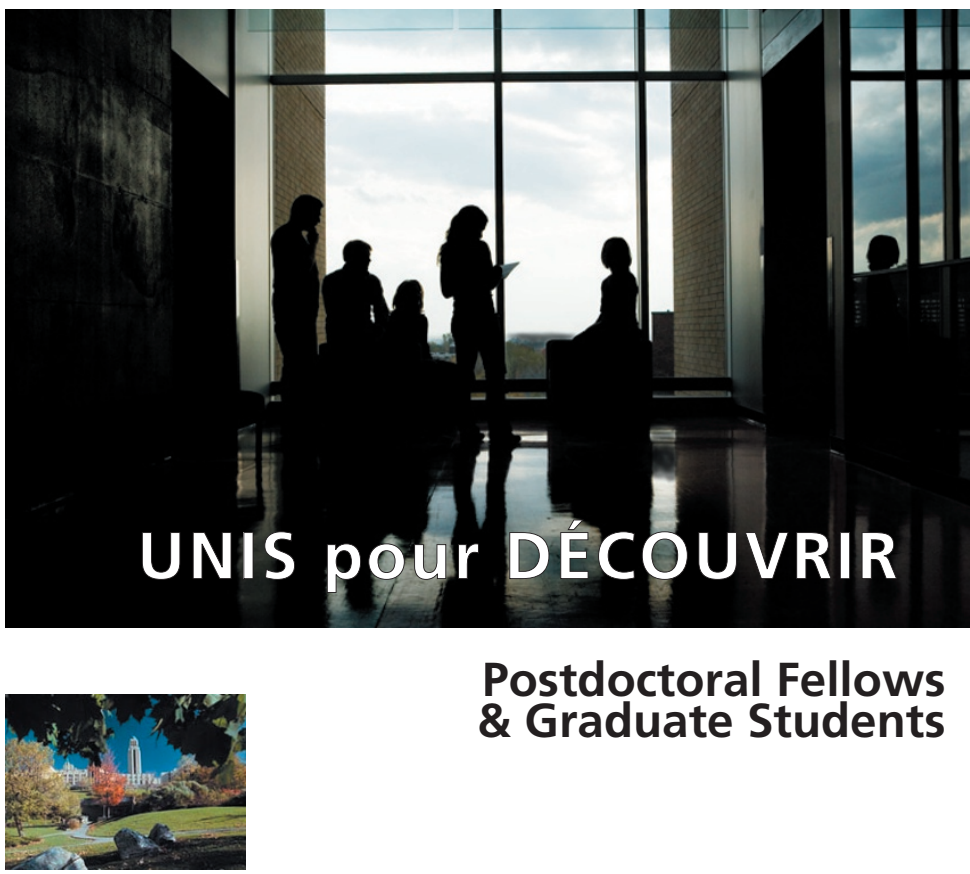

Postdoctoral Fellows \& Graduate Students
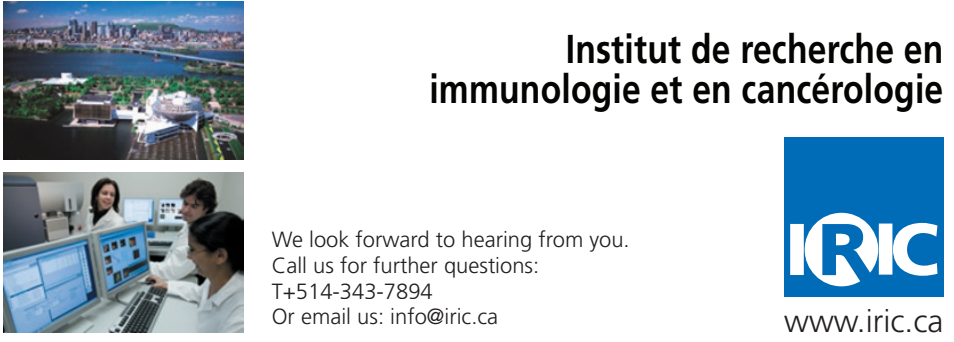

NW101222R

\title{
RETROSCREEN
}

\section{Various positions Competitive Packages London}

\section{ww w. retroscreen.com conquering viral disease}

Retroscreen Virology is Europe's leading contract virology research company providing both contract pre-clinical and clinical research as well as development work associated with the fight against respiratory viruses.

Our clients include leading international developers and suppliers of vaccines, antivirals and disinfectants. Our Scientists are encouraged to regularly publish scientific papers and participate in International Virology Conferences.

Well established with an experienced management team, following a recent round of investment, the company is looking to continue to grow and internationally expand its operations. As a result a number of candidates are being sought for the following roles:

\author{
Business Development Manager \\ Operations Manager \\ Clinical Trials Administration \& Support \\ Quality Assurance (GLP, GCP, ISO 9001) \\ Research Nurses \\ Study Directors \\ Research Scientists \\ Research Assistants \\ Part-time Statistician \\ Medical Writer
}

We are looking for suitably qualified individuals capable of excelling within a fast growing environment, being able to work within small teams delivering projects to tight deadlines. Roles may be flexible for the right individual. We would be particularly interested in individuals with experience in the influenza, avian influenza (H5N1), SARS, Respiratory Syncytial (RSV) and Common Cold Viruses.

Interested candidates should send a CV and accompanying letter to recruitment@protoscience.co.uk by email, identifying the role you are interested in together with contact information, as well as details of your current remuneration. The closing date for all applications is 31 st May 2007. 